\title{
Determination of Short-Chain Branches in Poly(vinyl chloride) and Ethylene-Vinyl Chloride Copolymers by Pyrolysis- Hydrogenation-Gas Chromatography
}

\author{
Shuncong Mao, Hajime Ohtani, Shin Tsuge, ${ }^{\dagger}$ Hiroshi Niwa, ${ }^{*}$ and Masatoshi Nagata* \\ Department of Applied Chemistry, Graduate School of Engineering, Nagoya University, \\ Furo-cho, Chikusa-ku, Nagoya 464-8603, Japan \\ * Yokkaichi Research Laboratory, Tosoh Corporation, \\ 1-8 Kasumi, Yokkaichi, Mie 510-8540, Japan
}

(Received August 10, 1998)

\begin{abstract}
Short-chain branches (SCB) of poly(vinyl chloride) (PVC) and ethylene-vinyl chloride copolymer (EVC) samples were determined by reduction of the samples with tri- $n$-butyltin hydride $\left(\mathrm{Bu}_{3} \mathrm{SnH}\right)$ followed by high-resolution pyrolysis-hydrogenation-gas chromatographic measurement in the presence of nickel $(\mathrm{Ni})$ as a hydrogenation catalyst. The branch contents were estimated from the relative peak intensities of characteristic key isoalkanes on the $C_{10}$ and $C_{11}$ fragment region in the observed pyrograms by comparing the data of reference model ethylene- $\alpha$-olefin copolymers with known contents of methyl $\left(\mathrm{C}_{1}\right)$, ethyl $\left(\mathrm{C}_{2}\right)$, and butyl $\left(\mathrm{C}_{4}\right)$ branches, respectively. The results obtained by this method were in reasonably good agreement with those found by ${ }^{13} \mathrm{C}$ NMR. The correlations between polymerization conditions and the SCB contents in the PVC and EVC samples were also discussed. Significant features of the proposed method such as extremely high sensitivity using less than $1 \mathrm{mg}$ of the sample and rapidness to finish one run in about $1 \mathrm{~h}$ would meet the potential needs for the SCB characterization in various polymers containing chlorine, which were used in practical fields.
\end{abstract}

KEY WORDS Poly(vinyl chloride) / Ethylene-Vinyl Chloride Copolymers / Short-Chain Branches / Pyrolysis-Hydrogenation-Gas Chromatography /

Poly(vinyl chloride) (PVC) and ethylene-vinyl chloride copolymers (EVC) have been among the most widely used polymers because of their excellent cost/performance despite their possible environmental hazard. It has been recognized that morphology and many physical properties of PVC and EVC are dependent upon the kind and the amount of short-chain branches (SCB) along the polymer backbone. Although in early days, IR and $\gamma$-radiolysis had been used to study branch structures in PVC, those methods often liable to give disagreeing values of the kind and the amount of branching. Owing to the drastic advances in superconductivity NMR, the SCB numbers of PVC and EVC have been most extensively studied by ${ }^{13} \mathrm{C}$ NMR. ${ }^{1-7}$ However, because of stereochemical complications and lack of chemical-shift reference data, it was often difficult to determine the detailed microstructures of PVC and its copolymers directly by ${ }^{13} \mathrm{C}$ NMR. Therefore, in most of the studies, PVC and its copolymers were generally reductively dehalogenated into their polyethylene (PE) skeletal structures before spectroscopic characterization because the spectra of the reduced samples can provide significant amounts of information about the structures of the original polymers.

Bovey et al. ${ }^{1}$ identified the $\mathrm{C}_{1}$ branch structure $\left(-\mathrm{CH}_{2} \mathrm{C}(\mathrm{Cl}) \mathrm{H}-\mathrm{C}\left(\mathrm{CH}_{2} \mathrm{Cl}\right) \mathrm{H}-\mathrm{CH}_{2} \mathrm{C}(\mathrm{Cl}) \mathrm{H}-\right)$ in $\mathrm{LiAlH}_{4}-$ reduced PVC by ${ }^{13} \mathrm{C}$ NMR. Starnes et al. ${ }^{2}$ elucidated the mechanism of the branch formation in PVC by means of ${ }^{13} \mathrm{C}$ NMR for $\mathrm{LiAlH}_{4}$-reduced poly(vinyl- $\alpha-d$ chloride). The same authors ${ }^{3}$ also demonstrated that the presence of $\mathrm{C}_{4}$ branch in the PVC might be a result of radical "back-biting" reaction by use of the ${ }^{13} \mathrm{C}$ NMR spectra of reductive dehalogenated PVC samples. They also confirmed by the same method that branch

\footnotetext{
${ }^{\dagger}$ To whom all correspondence should be addressed.
}

contents were in the order of $\mathrm{C}_{1}>\mathrm{C}_{4}>\mathrm{C}_{2}$ and that no evidence was observed for the existence of $\mathrm{C}_{3}$ and $\mathrm{C}_{5}$ branches in PVC. ${ }^{5}$ In our previous papers. ${ }^{7} \mathrm{C}_{1}, \mathrm{C}_{2}$, and $\mathrm{C}_{4}$ branches in EVC have been determined by ${ }^{13} \mathrm{C}$ NMR for $\mathrm{Bu}_{3} \mathrm{SnH}$-reduced EVC samples.

On the other hand, high-resolution pyrolysis-hydrogenation-gas chromatography (Py-HGC) has been demonstrated to be a valuable technique for studying the branch structures in PE and PVC. ${ }^{4,8,9,10}$ In these reports, the amounts of SCB were estimated from the relative peak intensities of the characteristic key isoalkanes on the observed pyrograms by use of either platinum $(\mathrm{Pt})$ or palladium $(\mathrm{Pd})$ hydrogenation catalyst where the data for reference model ethylene- $\alpha$-olefin copolymers with known branch contents were used for calibration.

Ahlstrom et al. ${ }^{8}$ determined $\mathrm{C}_{1}$ and $\mathrm{C}_{2}$ branches in reductively dehalogenated PVC by Py-HGC using Pd hydrogenation catalyst based on $\mathrm{C}_{7}$ and $\mathrm{C}_{8}$ fragment regions on the pyrograms. However, only semi-quantitative results were obtained mainly because of insufficient peak separation. In addition, Liebman et al. $^{4}$ also determined $\mathrm{C}_{1}, \mathrm{C}_{2}$, and $\mathrm{C}_{4}$ branches in reduced PVC by Py-HGC using the same catalyst and a fusedsilica capillary column based on $\mathrm{C}_{12}$ fragment region in the pyrograms combined with a computer simulation technique. This method, however, was limited at most to an inherent detection level of 1 branch/1000 carbon atoms along the polymer chain mostly because of still insufficient resolution of the specific isoalkane peaks on the resulting pyrograms obtained by using the fused silica capillary column at the early days.

In this work, high-resolution Py-HGC was applied to develop a new practical method to determine the amounts of the SCB in PVC and EVC where reductively dehalogenated PVC and EVC samples prepared by 
Table I. Poly(vinyl chloride) samples ${ }^{\mathrm{a}}$

\begin{tabular}{|c|c|c|c|c|c|c|c|}
\hline \multirow{2}{*}{ Sample } & \multirow{2}{*}{$\frac{\text { Polym. time }}{\mathrm{b}}$} & \multirow{2}{*}{$\frac{\text { Conv. }^{\mathrm{c}}}{\%}$} & \multirow{2}{*}{$\begin{array}{c}M_{w} \\
\left(\times 10^{-5}\right)\end{array}$} & \multirow{2}{*}{$M_{w} / M_{n}$} & \multicolumn{3}{|c|}{ Branch contents by ${ }^{13} \mathrm{CNMR}^{\mathrm{d}}$} \\
\hline & & & & & $\mathrm{C}_{1}$ & $\mathrm{C}_{2}$ & $\mathrm{C}_{4}$ \\
\hline PVC-1 & 0.5 & 6.3 & 0.76 & 2.0 & 1.6 & 0.2 & 0.3 \\
\hline PVC-2 & 1 & 10.2 & 0.85 & 2.0 & 3.0 & 0.3 & 0.5 \\
\hline PVC-3 & 2 & 22.6 & 0.91 & 2.0 & 5.0 & 0.5 & 0.7 \\
\hline PVC-4 & 3 & 38.5 & 0.93 & 2.1 & 4.1 & 0.5 & 0.8 \\
\hline PVC-5 & 4 & 55.1 & 0.97 & 2.0 & 3.1 & 0.4 & 0.8 \\
\hline PVC-6 & 5 & 70.1 & 0.98 & 2.0 & 3.6 & 0.7 & 0.7 \\
\hline PVC-7 & 6 & 81.0 & 1.00 & 2.0 & 4.1 & 0.8 & 1.1 \\
\hline PVC-8 & 7 & 86.7 & 0.99 & 2.1 & 3.7 & 0.8 & 1.5 \\
\hline PVC-9 & 8 & 93.5 & 1.00 & 2.1 & 4.4 & 1.1 & 1.7 \\
\hline
\end{tabular}

${ }^{\text {a }}$ Polymerization conditions: suspension polymerization initiated by benzoylperoxide in the presence of dispersing agent, polyvinylalcohol by use of an 501 autoclave at $55^{\circ} \mathrm{C}$ under an initial pressure of $15 \mathrm{~kg} \mathrm{~cm}^{-2}$. ${ }^{\text {b }}$ Polymerization time: $0.5-8 \mathrm{~h}$. ${ }^{\mathrm{c}} \mathrm{Conversion}$ : percent. ${ }^{\mathrm{d}} \mathrm{The} \mathrm{SCB}$ number/1000 vinyl chloride monomer units.

Table II. Ethylene-vinyl chloride samples ${ }^{\mathrm{a}}$

\begin{tabular}{|c|c|c|c|c|c|c|c|c|}
\hline \multirow{3}{*}{ Sample } & \multicolumn{3}{|c|}{ Ethylene content $/ \mathrm{mol} \%$} & \multirow{3}{*}{$\begin{array}{c}M_{w} \\
\left(\times 10^{-4}\right)\end{array}$} & \multirow{3}{*}{$M_{w} / M_{n}$} & \multicolumn{3}{|c|}{ Branch contents by ${ }^{13} \mathrm{C} \mathrm{NMR}^{\mathrm{b}}$} \\
\hline & \multirow{2}{*}{ In feed } & \multicolumn{2}{|c|}{ In copolymer } & & & & & \\
\hline & & ${ }^{1} \mathrm{H}$ NMR & IR & & & $\mathrm{C}_{1}$ & $\mathrm{C}_{2}$ & $\mathrm{C}_{4}$ \\
\hline EVC-1 & 2.7 & 2.0 & 2.2 & 13.5 & 2.6 & 3.8 & 0.7 & 0.7 \\
\hline EVC-2 & 6.3 & 5.3 & 5.9 & 13.8 & 2.1 & 4.3 & 0.6 & 1.3 \\
\hline EVC-3 & 9.0 & 7.8 & 9.0 & 13.9 & 2.1 & 4.5 & 1.1 & 1.5 \\
\hline EVC-4 & 17.9 & 11.1 & - & 15.3 & 2.3 & 4.8 & 1.0 & 2.2 \\
\hline
\end{tabular}

${ }^{\mathrm{a}}$ The polymerization conditions are basically the same as those for PVCs in Table I except for the fed monomers. ${ }^{\mathrm{b}}$ The SCB number/1000 vinyl chloride monomer units.

using basically the same way reported in the previous papers $^{7}$ was used. Here, various hydrogenation catalysts such as $\mathrm{Pt}, \mathrm{Pd}$, and nickel $(\mathrm{Ni})$ were examined for Py-HGC, and various calculation methods were tested for the observed pyrograms to obtain comparable values of the kind and the amount of branches estimated by ${ }^{13} \mathrm{C}$ NMR.

\section{EXPERIMENTAL}

\section{Sample}

Nine PVC and four EVC samples used in this study are listed in Tables I and II, respectively. The four EVC and their reduced products are the same materials used in the previous work, ${ }^{7}$ and the nine PVC samples were synthesized under basically the same polymerization conditions for the EVCs except for the feeded monomer. The nine PVC samples are also reductively dehalogenated into the PE skeletal structures by using tri- $n$-butyltin hydride $\left(\mathrm{Bu}_{3} \mathrm{SnH}\right)$ with basically the same procedure reported elsewhere. ${ }^{7,11,12}$ In PVC, the main SCB structures have been reported to be $\mathrm{C}_{1}\left(-\mathrm{CH}_{2} \mathrm{Cl}\right), \mathrm{C}_{2}$ $\left(-\mathrm{CH}_{2} \mathrm{CH}_{2} \mathrm{Cl}\right)$, and $\mathrm{C}_{4}\left(-\mathrm{CH}_{2} \mathrm{CHClCH}_{2} \mathrm{CH}_{2} \mathrm{Cl}\right)$. These SCB structures are thus converted to methyl $\left(\mathrm{C}_{1}\right)$, ethyl $\left(\mathrm{C}_{2}\right)$, and butyl $\left(\mathrm{C}_{4}\right)$ branches in PE skeletal structures by reductive dehalogenation. Furthermore, three model samples, ethylene-propylene (EP), ethylene-1-butene (EB), and ethylene-1-hexene (EH) copolymers, of which branch contents are known to be 20 methyl, 24 ethyl, and 18 butyl per $1000 \mathrm{C}$, respectively, were also used, which are the same materials used in the previous work for SCB determination in PE. ${ }^{10}$

\section{Py-HGC Conditions}

The Py-HGC system utilized in this work is basically the same as that described previously. ${ }^{9,10}$ A vertical microfurnace-type pyrolyzer (Yanaco GP-1018) was directly attached to a gas chromatograph (HP 5890 SERIES II) equipped with a flame ionization detector (FID) and a fused-silica capillary column $(50 \mathrm{~m} \times 0.2$ $\mathrm{mm}$ i.d.) coated with immobilized crosslinked methyl silicone gum $(0.33 \mu \mathrm{m}$ film thickness $)$ supplied by Hewlett-Packard (Ultra 1). A weighed sample of $c a$. $200 \mu \mathrm{g}$ was pyrolyzed at $650^{\circ} \mathrm{C}$ under a flow of hydrogen carrier gas $\left(50 \mathrm{ml} \mathrm{min}{ }^{-1}\right)$. The glass insert tube with i.d. of $4 \mathrm{~mm}$ in the injection port was packed with hydrogenation catalyst of $c a .2 \mathrm{~cm}$ long. In this work, three kinds of hydrogenation catalysts, $5 \mathrm{wt} \% \mathrm{Pt}$ on $80 / 100$ mesh Diasolid H, $2 \mathrm{wt} \% \mathrm{Pd}$ on $80 / 100$ mesh Uniport HP and $5 \mathrm{wt} \% \mathrm{Ni}$ on $60 / 80$ mesh Diasolid $\mathrm{H}$, were used. In the upper part of the glass insert tube, $5 \mathrm{wt} \%$ of OV-101 on 80/100 mesh Diasolid H was also packed $c a .1 \mathrm{~cm}$ long to protect the catalyst from waxy and less volatile degradation products. The hydrogenation catalyst and OV-101 packing layer were separated and sandwiched by small quartz wool plug. The injection port was maintained at the optimum hydrogenation temperature of $200^{\circ} \mathrm{C}$. $^{10}$ The hydrogenated products passed through the catalyst tube were introduced into the separation column with a splitting ratio of $50: 1$. In order to get the optimum separation of the products in $C_{10}$ and $C_{11}$ region on the pyrogram clearly, the separation column temperature was initially set at $40^{\circ} \mathrm{C}$, then programmed at a rate of $3^{\circ} \mathrm{Cmin}^{-1}$ to $130^{\circ} \mathrm{C}$, and continued to program at a rate of $10^{\circ} \mathrm{Cmin}^{-1}$ up to $300^{\circ} \mathrm{C}$. Thus separated components were detected by 


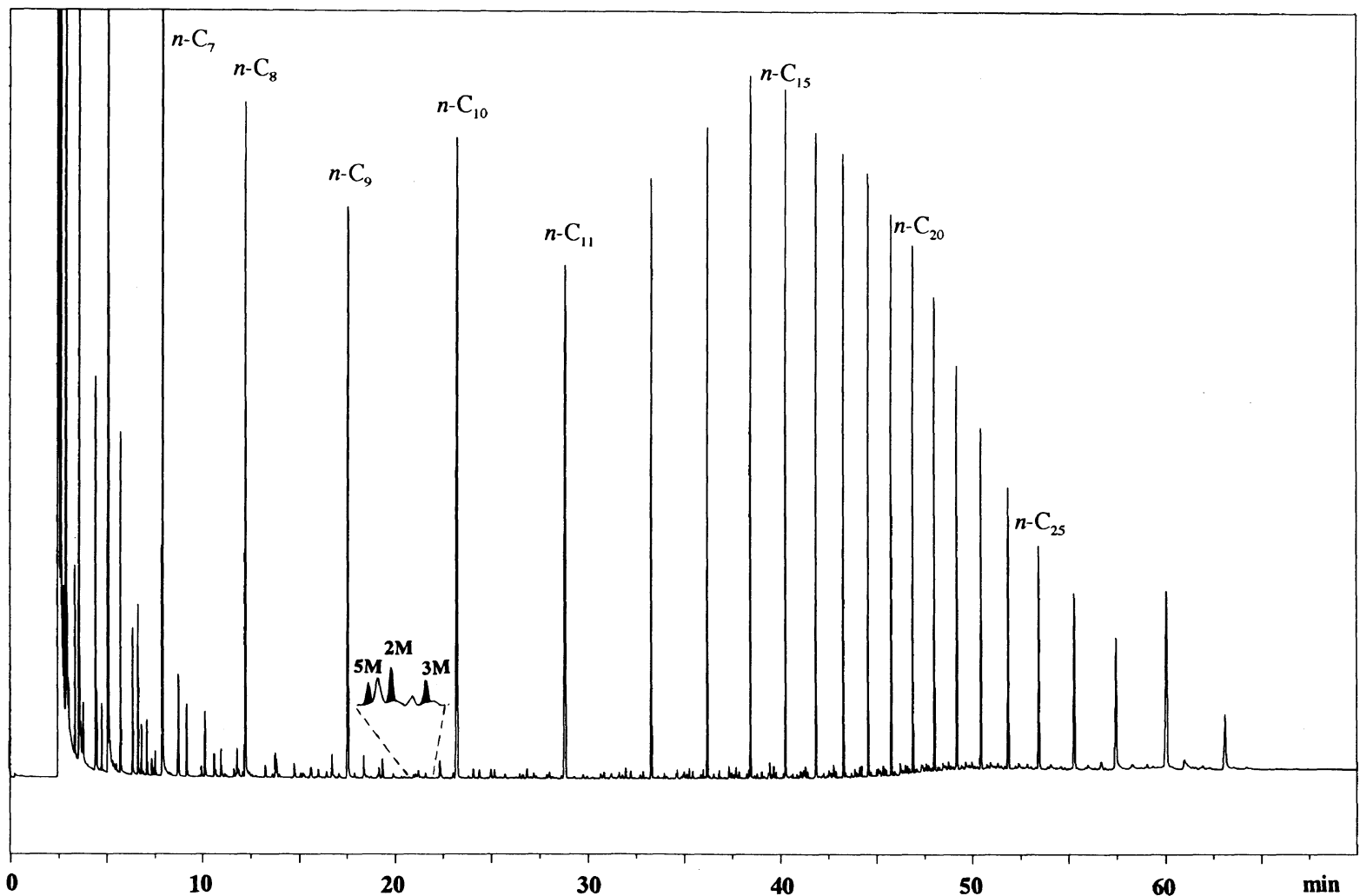

Figure 1. Typical pyrogram of a reductively dehalogenated PVC at $650^{\circ} \mathrm{C}$ observed after in-line hydrogenation using Ni catalyst. Sample, PVC-6; $n$ - $\mathrm{C}_{n}, n$-alkane with carbon number $n ; 2 \mathrm{M}, 2$-methylnonane; $3 \mathrm{M}, 3$-methylnonane; $5 \mathrm{M}, 5$-methylnonane.

Table III. Relative peak intensities of isoalkanes to key peak in the $\mathrm{C}_{10}$ region, and observed correlation factor for model ethylene- $\alpha$-olefin copolymers

\begin{tabular}{lcccccc}
\hline \multirow{2}{*}{ Reference sample } & $\begin{array}{c}\text { Branch content } \\
\text { per } 1000 \mathrm{C}\end{array}$ & $I(\mathrm{key})_{\mathrm{obs}^{\mathrm{a}}}$ & $f^{\mathrm{b}}$ & \multicolumn{3}{c}{ Relative peak intensities of isoalkanes to key peak } \\
\cline { 5 - 7 } & & & $2 \mathrm{M}$ & $3 \mathrm{M}$ & $5 \mathrm{M}$ \\
\hline P(ethylene-co-propylene) & $20 \mathrm{C}_{1}$ & $51.5(2 \mathrm{M})$ & 388 & 1.00 & 0.093 & 0.097 \\
P(ethylene-co-1-butene) & $24 \mathrm{C}_{2}$ & $52.9(3 \mathrm{M})$ & 453 & 0.489 & $\underline{1.00}$ & 0.052 \\
P(ethylene-co-1-hexene) & $18 \mathrm{C}_{4}$ & $62.0(5 \mathrm{M})$ & 290 & 0.164 & 0.080 & $\underline{1.00}$ \\
\hline
\end{tabular}

${ }^{\mathrm{a}}$ Key peak intensities relative to peak intensities of $I\left(n-\mathrm{C}_{10}\right)_{\mathrm{obs}}=1000 .{ }^{\mathrm{b}}$ Calculated correlation factor defined by eq $1 .{ }^{\mathrm{c}} \mathrm{The}$ underlined values are those for the key peaks.

FID. The peak identification was mostly carried out by using a gas chromatograph-mass spectrometer (JEOL Automass system II) to which the same pyrolyzer, the hydrogenation catalyst, and the separation column were also attached by using hydrogen carrier gas.

\section{RESULTS AND DISCUSSION}

Figure 1 shows a typical pyrogram of reductively dehalogenated PVC (PVC-6) at $650^{\circ} \mathrm{C}$ where Ni catalyst is used for the in-line hydrogenation. The pyrogram mainly consisting of serial $n$-alkane peaks is basically the same as that of PE. ${ }^{9,10}$ Various minor peaks, such as $2 \mathrm{M}, 3 \mathrm{M}$, and $5 \mathrm{M}$ in the $\mathrm{C}_{10}$ region, observed in-between the main $n$-alkane peaks are isoalkanes which reflect the branch structures in the polymer chain. Each branch content in the reductively dehalogenated PVCs was determined by the peak simulation using well-defined ethylene- $\alpha$-olefin model copolymers with known amounts of respective branch structure. Here, only $\mathrm{C}_{1}, \mathrm{C}_{2}$, and $\mathrm{C}_{4}$ branches were assumed to be present in PVC according to the foregoing ${ }^{13} \mathrm{C}$ NMR studies, and 2-methylnonane $(2 \mathrm{M})$, 3-methylnonane (3M) and 5methylnonane $(5 \mathrm{M})$ were selected as the key products for $\mathrm{C}_{1}, \mathrm{C}_{2}$, and $\mathrm{C}_{4}$ branching, respectively, which were the most intense isoalkane peaks in the corresponding model copolymers. The calculation of branch contents was carried out based on the relative peak intensities of the $\mathrm{C}_{10}$-isoalkanes to $n$-decane $\left(n-\mathrm{C}_{10}\right)$ in the pyrograms. The correlation factors $(f)$ for the content of branches were calculated first from the corresponding data for the model copolymers with known branch content.

$$
\begin{gathered}
{\left[I\left(\mathrm{C}_{i}\right)_{\mathrm{obs}} / I\left(n-\mathrm{C}_{10}\right)_{\mathrm{obs}}\right] \times 1000 \times f=I(\mathrm{key})_{\mathrm{obs}} \times f} \\
=\text { branch number } / 1000 \mathrm{C}
\end{gathered}
$$

where $I\left(\mathrm{C}_{i}\right)_{\mathrm{obs}}$ is the observed peak intensity of the key isoalkane for $C_{i}$ branching, and $i=1,2$ or 4 . $I\left(n-C_{10}\right)_{\text {obs }}$ is the observed peak intensity of $n-\mathrm{C}_{10}$ alkanes(decane). $I(\mathrm{key})_{\mathrm{obs}}$ is the relative peak intensity of the key isoalkane when the observed peak intensity of $n-\mathrm{C}_{10}$ alkanes were regarded as $1000\left[\left(I\left(n-C_{10}\right)_{\text {obs }}=1000\right)\right]$. 
Table III summarizes the observed $I(\text { key })_{\text {obs }}$ and the calculated $f$ values together with the relative peak intensities of the isoalkanes to the corresponding key peaks for the $\mathrm{C}_{10}$ region on the pyrograms of the model copolymers. Because each key peak is not completely independent of others, as pointed out in the previous paper, ${ }^{9}$ the effective peak intensity, $I_{\text {eff }}$ for each key peak on the $\mathrm{C}_{10}$ region can be calculated by solving the following simultaneous eq 2 when the mutual contributions of the other key peaks observed for the three model copolymers shown in the Table III are considered.

$$
\left.\begin{array}{l}
I(2 \mathrm{M})_{\mathrm{eff}}+0.093 I(3 \mathrm{M})_{\mathrm{eff}}+0.097 I(5 \mathrm{M})_{\mathrm{eff}}=I(2 \mathrm{M})_{\mathrm{obs}} \\
0.489 I(2 \mathrm{M})_{\mathrm{eff}}+I(3 \mathrm{M})_{\mathrm{eff}}+0.052 I(5 \mathrm{M})_{\mathrm{eff}}=I(3 \mathrm{M})_{\mathrm{obs}} \\
0.164 I(2 \mathrm{M})_{\mathrm{eff}}+0.080 I(3 \mathrm{M})_{\mathrm{eff}}+I(5 \mathrm{M})_{\mathrm{eff}}=I(5 \mathrm{M})_{\mathrm{obs}}
\end{array}\right\}(2)
$$

where $I(2 \mathrm{M})_{\mathrm{obs}}, I(3 \mathrm{M})_{\mathrm{obs}}$ and $I(5 \mathrm{M})_{\mathrm{obs}}$ are the observed relative peak intensities of the corresponding isoalkanes on the pyrogram of a given reductively dehalogenated PVC regarding the peak intensity of $n$-decane as 1000 $\left[\left(I\left(n-\mathrm{C}_{10}\right)_{\mathrm{obs}}=1000\right)\right]$.

Table IV. Observed and effective intensities of key peaks

\begin{tabular}{lccc}
\hline & \multicolumn{3}{c}{ Relative intensity of key peaks ${ }^{\mathrm{a}}$} \\
\cline { 2 - 4 } Sample & $I(2 \mathrm{M})$ & $I(3 \mathrm{M})$ & $I(5 \mathrm{M})$ \\
\hline PVC-1 & $2.5(3.4)$ & $0.1(1.6)$ & $0.6(1.8)$ \\
PVC-2 & $2.9(3.9)$ & $0.7(2.5)$ & $0.6(1.8)$ \\
PVC-3 & $5.0(6.5)$ & $0.6(3.4)$ & $0.6(2.2)$ \\
PVC-4 & $3.8(5.1)$ & $1.2(3.6)$ & $0.7(2.2)$ \\
PVC-5 & $3.7(5.0)$ & $0.7(3.0)$ & $0.7(2.3)$ \\
PVC-6 & $3.9(5.3)$ & $0.6(3.0)$ & $1.0(2.9)$ \\
PVC-7 & $4.2(5.7)$ & $0.5(3.0)$ & $1.0(2.9)$ \\
PVC-8 & $3.9(5.3)$ & $1.2(3.7)$ & $1.4(3.5)$ \\
PVC-9 & $5.3(7.3)$ & $1.2(4.6)$ & $2.0(5.0)$ \\
\hline
\end{tabular}

${ }^{a}$ Values relative to $I\left(n-C_{10}\right)_{\text {obs }}=1000$. Effective intensities are given first, and observed ones are given in parentheses.
Thus calculated $I_{\text {eff }}$ 's for the nine reductively dehalogenated PVCs in $\mathrm{C}_{10}$ region are listed in the Table IV along with the observed values, $I_{\text {obs }}$ 's. Subsequently, the SCB contents in reductively dehalogenated PVC are calculated by multiplying the $I_{\text {eff }}$ by the corresponding correction factor, $f$, in Table III according to basically the same relation as in eq 1. Additionally, the SCB contents were estimated in a similar manner for the peak intensities in $\mathrm{C}_{11}$ fragment region, and for the data obtained using various hydrogenation catalysts for PyHGC. Thus calculated SCB contents were comparatively summarized in the Table V. Here, the relative peak intensity $I(\mathrm{key})_{\mathrm{obs}}$ observed on the pyrograms was within $1.5 \%$ of relative standard deviation (RSD) for three repeated runs, while the estimated branching amounts by use of $I(\mathrm{key})_{\mathrm{obs}}$ and $f$ values estimated from the model copolymers were within $5.5 \%$ RSD for three repeated runs.

Among the results shown in Table $\mathrm{V}$, the branch contents calculated by the $\mathrm{C}_{10}$ fragment data obtained by use of $\mathrm{Ni}$ hydrogenation catalyst proved to be much closer to those estimated by ${ }^{13} \mathrm{C}$ NMR. This fact suggests that $\mathrm{Ni}$ which is known to be as a less active hydrogenation catalyst than Pt and Pd would be a better catalyst for this purpose. Thus obtained results calculated by the $\mathrm{C}_{10}$ fragment data taken by use of $\mathrm{Ni}$ catalyst (Table $\mathrm{V}$ ) exhibit a tendency that $\mathrm{C}_{2}$ and $\mathrm{C}_{4}$ contents increase with the increase of the conversion, while $\mathrm{C}_{1}$ content proved to be almost constant except for the PVC samples at lower conversions up to $c a$. $10 \%$. On the other hand, observed SCB contents obtained by use of $\mathrm{Pt}$ or $\mathrm{Pd}$ hydrogenation catalyst gave generally fairly big deviations from those by ${ }^{13} \mathrm{C}$ NMR, suggesting too strong catalytic actions to trigger undesirable sidereactions during hydrogenation of unsaturated double bond in the pyrolysis products to cause apparently higher branch contents than they were. The observations that

\begin{tabular}{|c|c|c|c|c|c|c|c|c|c|c|c|}
\hline \multirow{2}{*}{$\begin{array}{l}\text { Fragment } \\
\text { region }\end{array}$} & \multirow[b]{2}{*}{ Sample } & \multirow{2}{*}{$\frac{\text { Conv. }}{\%}$} & \multicolumn{9}{|c|}{ Branch contents/ 1000 chloride monomer units } \\
\hline & & & \multicolumn{3}{|c|}{$\mathrm{Ni}^{\mathrm{a}}$} & \multicolumn{3}{|c|}{$\mathrm{Pt}$} & \multicolumn{3}{|c|}{$\mathrm{Pd}$} \\
\hline \multirow{9}{*}{$\mathrm{C}_{10}$} & PVC-1 & 6.3 & $1.8(1.6)$ & $0.5(0.2)$ & $0.4(0.3)$ & 5.5 & 4.1 & 2.0 & 5.3 & 1.5 & 1.4 \\
\hline & PVC-2 & 10.2 & $2.5(3.0)$ & $0.5(0.3)$ & $0.7(0.5)$ & 5.3 & 3.8 & 1.4 & 5.3 & 1.0 & 1.4 \\
\hline & PVC-3 & 22.6 & $3.8(5.0)$ & $0.7(0.5)$ & $1.0(0.7)$ & 5.4 & 3.8 & 1.8 & 4.1 & 1.3 & 1.9 \\
\hline & PVC-4 & 38.5 & $3.2(4.1)$ & $0.9(0.5)$ & $1.1(0.8)$ & 5.1 & 3.3 & 1.9 & 3.8 & 1.2 & 0.7 \\
\hline & PVC-5 & 55.1 & $3.2(3.1)$ & $0.9(0.4)$ & $1.1(0.8)$ & 5.8 & 3.5 & 1.8 & 4.4 & 1.6 & 0.7 \\
\hline & PVC-6 & 70.1 & $3.4(3.6)$ & $1.0(0.7)$ & $1.1(0.7)$ & 5.8 & 3.6 & 2.1 & 4.6 & 1.5 & 1.0 \\
\hline & PVC-7 & 81.0 & $3.6(4.1)$ & $1.0(0.8)$ & $1.2(0.7)$ & 5.6 & 3.9 & 2.1 & 4.5 & 1.5 & 1.8 \\
\hline & PVC-8 & 86.7 & $3.8(3.7)$ & $1.1(0.8)$ & $1.6(1.5)$ & 5.9 & 3.7 & 2.1 & 4.6 & 1.4 & 1.3 \\
\hline & PVC-9 & 93.5 & $4.2(4.4)$ & $1.4(1.1)$ & $1.7(1.7)$ & 4.3 & 4.1 & 3.0 & 6.0 & 1.6 & 1.8 \\
\hline \multirow{7}{*}{$\mathrm{C}_{11}$} & PVC-1 & 6.3 & 3.2 & 1.7 & 0.3 & 5.9 & 3.9 & 3.5 & 6.4 & 0.1 & 0.5 \\
\hline & PVC-4 & 38.5 & 2.9 & 1.3 & 0.5 & 5.5 & 4.4 & 3.4 & 6.3 & 0.6 & 0.2 \\
\hline & PVC-5 & 55.1 & 2.9 & 1.4 & 0.6 & 5.7 & 3.6 & 4.8 & 6.7 & 0.2 & 0.2 \\
\hline & PVC-6 & 70.1 & 3.4 & 2.1 & 0.7 & 6.3 & 4.1 & 3.6 & 5.5 & 1.2 & 0.9 \\
\hline & PVC-7 & 81.0 & 3.4 & 1.7 & 0.6 & 6.1 & 3.4 & 4.1 & 5.6 & 0.7 & 0.9 \\
\hline & PVC-8 & 86.7 & 3.8 & 2.1 & 0.8 & 6.3 & 3.5 & 4.0 & 6.2 & 1.1 & 1.5 \\
\hline & PVC-9 & 93.5 & 4.6 & 2.6 & 0.7 & 5.9 & 4.3 & 3.8 & 5.8 & 1.1 & 1.0 \\
\hline
\end{tabular}

Table V. SCB contents in PVC obtained by Py-HGC using various hydrogenation catalysts and different fragment regions

${ }^{a}$ The SCB contents determined by ${ }^{13} \mathrm{C}$ NMR are given in parentheses. 
Table VI. SCB contents in EVC determined by Py-HGC and ${ }^{13} \mathrm{C}$ NMR

\begin{tabular}{|c|c|c|c|}
\hline \multirow{2}{*}{ Sample } & \multicolumn{3}{|c|}{ Branch contents/1000 vinyl chloride monomers ${ }^{a}$} \\
\hline & $C_{1}$ & $\mathrm{C}_{2}$ & $\mathrm{C}_{4}$ \\
\hline EVC-1 & $3.3(3.8)$ & $0.6(0.7)$ & $0.5(0.7)$ \\
\hline EVC-2 & $4.2(4.3)$ & $1.0(0.6)$ & $1.3(1.3)$ \\
\hline EVC-3 & $4.6(4.5)$ & $1.2(1.1)$ & $1.6(1.5)$ \\
\hline EVC-4 & $5.2(4.8)$ & $1.9(1.0)$ & $2.2(2.2)$ \\
\hline
\end{tabular}

a The SCB contents by $\mathrm{Py}-\mathrm{HGC}$ are obtained based on the $\mathrm{C}_{10}$ region using $\mathrm{Ni}$ catalyst, and those obtained by ${ }^{13} \mathrm{C}$ NMR are given in parentheses.

some additional new peaks were detected in the isoalkane regions of the pyrogram taken by use of $\mathrm{Pt}$ catalyst, and that relative yields of low-boiling point products eluted before $5 \mathrm{~min}$ in the pyrogram for $\mathrm{Pd}$ catalyst were approximately twice as much as those for the other catalysts also implicitly support the contribution of the side-reactions in the presence of $\mathrm{Pt}$ or $\mathrm{Pd}$ other than simple hydrogenation. On the other hand, the observed results based on the $C_{11}$ region were not completely consistent with those by NMR even for Ni catalyst. These discrepancies might be caused by some overlapping of additional products on the key isoalkane peaks in the $\mathrm{C}_{11}$ region on the pyrograms of the dehalogenated PVCs. This could be improved by using the other separation column with higher resolution.

Then, the same Py-HGC technique by use of $\mathrm{Ni}$ catalyst was applied to estimate the SCB contents in the EVC samples listed in Table II. Thus estimated branch contents for the reductively dehalogenated EVC samples are summarized in Table VI. The observed contents which were also in reasonably good agreement with those estimated by ${ }^{13} \mathrm{C}$ NMR shown in the parentheses clearly exhibit a tendency that the SCB contents slightly increase as a monotonously increasing function of ethylene contents in the EVC.

In the former study of low density PEs, ${ }^{10}$ the $\mathrm{C}_{11}$ region was empirically selected to estimate the amounts of five kinds of the SCBs $\left(\mathrm{C}_{1}, \mathrm{C}_{2}, \mathrm{C}_{4}, \mathrm{C}_{5}\right.$, and $\mathrm{C}_{6}$ ) using five different key isoalkane peaks, where the observed amounts of the shorter branches $\left(\mathrm{C}_{1}\right.$ and $\left.\mathrm{C}_{4}\right)$ had been pointed out to be overestimated than they were, probably because of still remaining some peak overlapping to the corresponding key peaks. In this study for PVCs and EVCs, however, only three isoalkane peaks were focused to be isolated among so many isomers, and therefore both the $C_{10}$ and $C_{11}$ region were carefully compared. As might be expected, much more deviation in the observed branching values for $\mathrm{C}_{1}$ and $\mathrm{C}_{4}$ were observed for the $C_{11}$ region, while those by the $C_{10}$ region gave, in turn, much better results because of the better resolution as for the particular three isoalkane peaks (2-methyl, 3-methyl, and 5-methyl nonane). The $\mathrm{C}_{10}$ region, however, did not still provide better results for the estimation of the SCBs in low density PEs because the whole resolution for the five key isoalkane peaks corresponding to $\mathrm{C}_{1}, \mathrm{C}_{2}, \mathrm{C}_{4}, \mathrm{C}_{5}$, and $\mathrm{C}_{6}$ branches in the $\mathrm{C}_{10}$ region proved to be poorer than that in the $\mathrm{C}_{11}$ one.

Since the developed method requires less than $1 \mathrm{mg}$ of the sample and provides a rapid and reproducible measurement within $1 \mathrm{~h}$ or so, it would have versatile applicability in the practical field of the SCB characterization for various polymers containing chlorine.

\section{REFERENCES}

1. F. A. Bovey, K. B. Abbas, F. C. Schilling, and W. H. Starnes, Jr., Macromolecules, 8, 43 (1975)

2. W. H. Starnes, Jr., F. C. Schilling, K. B. Abbas, R. E. Cais, and F. A. Bovey, Macromolecules, 12, 556 (1979).

3. W. H. Starnes, Jr., F. C. Schilling, I. M. Plitz, R. E. Cais, and F. A. Bovey, Polym. Bull., 4, 555 (1981).

4. S.Liebman, D. Ahlstrom, W. H. Starnes, Jr., and F. C. Schilling, J. Macromol. Sci.-Chem., A17, 935 (1982).

5. W. H. Starnes, Jr., F. C. Schilling, I. M. Plitz, R. E. Cais, D. J. Freed, R. L. Hartless, and F. A. Bovey, Macromolecules, 16, 790 (1983)

6. W. H. Starnes, Jr., Pure \& Appl. Chem., 57, 1001 (1984).

7. H. Niwa and M. Nagata, Kobunshi Ronbunshu, 52, 718 (1995).

8. D. Ahlstrom and S. Liebman, J. Polym. Sci., Polym. Chem. Ed., 14, 2479 (1976).

9. Y. Sugimura, T. Usami, T. Nagawa, and S. Tsuge, Macromolecules, 14, 1787 (1981)

10. H. Ohtani, S.Tsuge, and T. Usami, Macromolecules, 17, 2557 (1984).

11. T. Hjertberg and A. Wendel, Polymer, 23, 1641 (1982).

12. S. Mao, H. Ohtani, and S. Tsuge, Polymer, 1, 143 (1998). 